\title{
Current status in the management of uterine corpus cancer in Korea
}

\author{
Nan-Hee Jeong, Jong-Min Lee, Seon-Kyung Lee \\ Department of Obstetrics and Gynecology, Kyung Hee University School of Medicine, Seoul, Korea
}

\begin{abstract}
Uterine corpus cancer has increased in prevalence in Korean women over the last decade. Recently, elegant studies have been reported from many institutes. To improve treatment strategies, a review of our own data is warranted. This work will discuss the risks and prognostic factors for uterine corpus cancer, and the radiologic evaluation, prediction of lymph node metastasis, systematic lymphadenectomy, minimally invasive surgery, ovarian-saving surgery, fertility-sparing treatment, and adjuvant treatment in women with uterine cancer.
\end{abstract}

Key Words: Uterine neoplasms, Review

\section{INTRODUCTION}

Uterine corpus cancer is one of the most common female genital tract malignancies in many developed countries and has become more prevalent in Korean women over the last decade. ${ }^{1,2}$ Uterine corpus cancer accounts for approximately $4 \%$ of all newly diagnosed cancers and approximately $1.7 \%$ of cancer deaths in women worldwide. In 2002, an estimated 199,000 new cases of uterine corpus cancer and 50,000 cases of cancer-related deaths were expected worldwide. ${ }^{3}$ The association between obesity and increased risk of uterine corpus cancer is more significant than any other obesity-related cancer in reviews based on Western populations. ${ }^{4-8}$ Considering that the obesity is on the rise and uterine corpus cancer has become more prevalent, accounting for $3.7 \%$ of all newly diagnosed cancers in Korean women in $2005,{ }^{9}$ it is anticipated that uterine corpus cancer will become a more significant public health problem in the future in Korea.

Based on the American College of Obstetrics and Gynecologists (ACOG) recommendations and the newly revised surgical staging system by the International Federation of Gyneco-

Received June 3, 2010, Accepted June 27, 2010

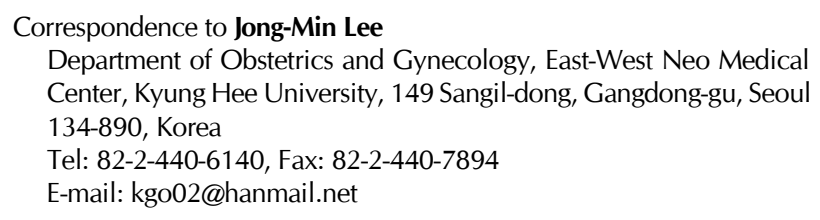

This research received the Grand Prize from the Korean Research Foundation of Gynecologic Cancer at the 25th Annual Meeting of the Korean Society of Gynecologic Oncology and Colposcopy. logy and Obstetrics (FIGO), the cornerstone of treatment for uterine corpus cancer patients is surgery, including peritoneal cytology, hysterectomy, bilateral salpingo-oophorectomy, lymphadenectomy, and complete resection of all extrauterine disease. ${ }^{10,11}$ Nevertheless, debate continues regarding surgical staging procedures, especially in terms of the role of, candidates for, and extent of lymphadenectomy.

The data in support of treatment strategies of uterine corpus cancer are conflicting. For example, several retrospective studies have suggested a therapeutic benefit associated with lymphadenectomy in early stage uterine corpus cancer, ${ }^{12,13}$ but recent randomized trials have failed to prove a survival advantage. ${ }^{14,15}$ Moreover, several randomized trials have shown no evidence of benefit for adjuvant radiation for early stage uterine corpus cancer in terms of overall survival. ${ }^{16,17}$ Thus, we are still at chaos with the limited randomized controlled trials and sometimes, contradictory treatment guidelines for uterine corpus cancer.

Considering the ethnic and epidemiologic difference in the susceptibility to uterine corpus cancer, and the relatively low incidence of uterine corpus cancer compared to cervical cancer, we need to analyze and understand the results of Korean studies. Recently, the interest of Korean researchers in uterine corpus cancer has increased and there have been many clinically meaningful results. Thus, this article reviews the current status of the management of uterine corpus cancer in Korea based on the recently published results.

\section{RISK FACTORS}

Nulliparity, obesity, unopposed estrogen use, late menopause, and diabetes are the well-established clinical risk fac- 
tors for the development of uterine corpus cancer. ${ }^{18}$ Most of these risk factors are primarily associated with prolonged exposure to unopposed estrogen. Obesity is an important risk factor for uterine corpus cancer. In Western populations, obesity has been associated with a 2- to 5-fold increase in endometrial cancer risk in both pre- and post-menopausal women, because extra-ovarian estrogen derived from androgens aromatized in adipose tissue plays an important role in the development of uterine corpus cancer. ${ }^{4}$ In Korea, Jeong et al. ${ }^{19}$ studied the effect of obesity on uterine corpus cancer risk in an age-matched case-control study, and found that both obese $\left(\mathrm{BMI} \geq 25 \mathrm{~kg} / \mathrm{m}^{2}\right)$ and overweight $\left(23 \mathrm{~kg} / \mathrm{m}^{2} \leq \mathrm{BMI}<25\right.$ $\mathrm{kg} / \mathrm{m}^{2}$ ) women had a significantly increased risk for endometrioid uterine cancer compared to non-obese women (BMI $<23 \mathrm{~kg} / \mathrm{m}^{2}$ ).

Recently, antioxidant micronutrients have received attention as an environmental and lifestyle risk factor for uterine corpus cancer. ${ }^{20,21}$ Two small Korean case-control studies have reported that plasma levels of $\beta$-carotene, lycopene, folate, and vitamin B12 are inversely associated with uterine corpus cancer risk; ${ }^{22,23}$ however, they failed to prove an association between the intake of folic acid and vitamin B12 and disease risk. ${ }^{23}$

Studies involving genetic single nucleotide polymorphisms (SNPs) for uterine corpus cancer have helped to explain the modest risk and differences in individual cancer susceptibility. Candidate genes may be involved in DNA damage repair, estrogen metabolism, carcinogen metabolism, cell-cycle control, apoptosis, and steroid receptor activation pathways. ${ }^{24}$ In this way, several results have indicated common genetic polymorphisms in Korean women that augment the effects of riskfactor exposure, such as p53, p21, CCND1, ERCC1, and HER2 genes; the results are summarized in Table $1 .{ }^{25-29} \mathrm{p} 53$, which is one of the representative tumor suppressor genes, and p21, which is a downstream mediator of p53, were examined by Roh et al. ${ }^{26}$ They found that the $\mathrm{p} 53$ genotypes containing the Pro allele at codon 72 and homozygous carriers of the p21 Ser allele at codon 31 were significantly associated with an increased risk of uterine corpus cancer. CCND1 is known as the gene involved in the normal cell cycle (the product of CCND1 is cyclin D1). An increased risk of uterine corpus cancer for the AA genotype of the G870A SNP in CCND1 was described by Kang et al. ${ }^{27}$ One study involving the C19007T SNP of excision repair cross-complementing group 1 (ERCC1) showed no evidence of an association with uterine corpus cancer risk. ${ }^{28}$ Two interesting studies reported that HER-2 SNPs did not significantly affect the risk for uterine corpus cancer and these results were repeated with an additional analysis in relation to body mass index and patient age. ${ }^{25,29}$

These studies were characterized by a single ethnicity, hospital-based case-control design, relatively small sample size, selection of hospital controls, and adjustment of clinical variables (eg, age, body mass index, reproductive history, and exogenous hormone use). Therefore, these findings remain to be confirmed by an additional population-based study.

\section{PREDICTION OF LYMPH NODE METASTASIS}

Lymph node (LN) metastasis, one of the most significant prognostic factors, was observed in approximately $13 \%$ of patients with uterine corpus cancer in a multicenter Korean study. ${ }^{30}$ Prediction of LN metastasis represents critical steps for planning the extent of surgery. To avoid unnecessary LN dissection and the associated surgical morbidity, several modalities, such as CT, MRI, PET/CT, and serum CA-125 levels, have been suggested for the prediction of $\mathrm{LN}$ metastasis (Table 2). ${ }^{31-37}$

Selman et al. ${ }^{38}$ conducted a meta-analysis to evaluate the accuracy of radiologic imaging to predict LN metastases, and found that MRI and sentinel node biopsy were more accurate than CT scanning. Similarly, there have been several efforts involving the performance of MRI for prediction of LN metastasis and deep myometrial invasion. Considering the clinical significance of LN metastasis, the tests to predict LN metastasis should have a high sensitivity and negative predictive value. The sensitivity and negative predictive value of MRI for LN metastasis were reported as $45-78 \%$ and $91-95 \%$, respectively (Table 2). This uncertainty might be caused by difficulty in differentiating metastatic nodes from hyperplastic nodes. ${ }^{39}$ Thus, we suggest that MRI shows unsatisfactory results in the prediction of LN metastasis and cannot replace surgical staging. This error with respect to LN metastasis was also ob-

Table 1. Association of genetic polymorphisms with uterine corpus cancer risk in Korean women

\begin{tabular}{lccllc}
\hline Author, year & Cases (n) & Controls (n) & Gene, position & \multicolumn{1}{c}{ Genotype } & OR (95\% CI) \\
\hline Roh $(2004)^{26}$ & 95 & 285 & p53, P72R & Arg/Pro+Pro/Pro vs. Arg/Arg & $3.56(2.10-6.04)$ \\
& & & p21, S31R & Ser/Ser vs. Arg/Arg + Arg/Ser & $2.68(1.59-4.51)$ \\
Kang $(2005)^{27}$ & 77 & 154 & cyclin D1, G870A & AA vs. GG+AG & $2.63(1.04-2.66)$ \\
Jo $(2007)^{28}$ & 102 & 302 & ERCC1, C19007T & CT + TT vs. CC & $0.91(0.57-1.44)$ \\
Tong (2009) & 125 & 302 & HER-2, rs1801200 & GA vs. AA & $1.13(0.59-2.16)$ \\
& & & HER-2, rs1810132 & TT vs. CC & $0.97(0.44-2.14)$ \\
& & & HER-2, rs2517951 & TT vs. CC & $1.40(0.67-2.00)$ \\
& & & HER-2, rs1058808 & GG vs. CC & $1.39(0.68-2.87)$ \\
\hline
\end{tabular}

OR: odds ratio, CI: confidence interval, ERCC1: excision repair cross-complementing group 1. 
served in clinical stage I disease ( $45.0 \%$ sensitivity, $\mathrm{n}=166)$, thus some investigators warned that an incorrect decision might be made for a number of patients based on a pre-operative MRI. ${ }^{35}$ MRI was not effective in the detection of paraaortic node metastasis as well. Park et al. ${ }^{32}$ described that 1 of 7 positive para-aortic LN areas were detected by MRI (sensitivity, $14.3 \%$ ), compared to 5 of 6 pelvic node areas (sensitivity, $83 \%) .{ }^{32}$ Yoo et $a .^{33}$ reported that MRI failed to detect any of 3 positive para-aortic nodes among 99 patients. On the other hand, Park et al. ${ }^{32}$ compared PET/CT with MRI for accuracy in detecting retroperitoneal metastasis in 53 women, and found that PET/CT had a higher sensitivity than MRI in detecting para-aortic or pelvic node metastasis, although the difference was insignificant $(69.2 \%$ vs. $46.2 \%, \mathrm{p}=0.250)$.

The sensitivity of CA-125 had a wide range of variation (Table 2). Nevertheless, CA-125 was suggested as an additive tool to predict LN metastasis. Han et al. ${ }^{34}$ examined the following 6 pre-operative factors to predict $\mathrm{LN}$ metastasis: age $\geq$ 55 years; serum CA-125 level ( $\geq 20 \mathrm{U} / \mathrm{mL}$ if $<50$ years of age; $\geq 28 \mathrm{U} / \mathrm{mL}$ if $\geq 50$ years of age); non-endometrioid histology; grade 3; metastatic LN assessed by pelvic MRI or CT; and deep myometrial invasion assessed by pelvic MRI only. In an analysis of 300 women, they reported $100 \%$ sensitivity and neg- ative predictive value combining the 6 pre-operative tests. Additionally, LN metastasis is highly correlated with the depth of myometrial invasion, ${ }^{30,40}$ and commonly used for the assessment of the risk of LN metastasis (Table 3). ${ }^{31,33-35,41-44}$ Prediction of myometrial invasion is also crucial in decisions as to whether conservative treatment should be administered to uterine corpus cancer patients. In this case, MRI is the preferred imaging modality in the prediction of myometrial invasion (Table 3). However, the sensitivity (36-90\%) and negative predictive values (83-94\%) of MRI in the detection of deep myometrial invasion was not satisfactory. Underestimation of myometrial invasion was associated with an isotense junctional zone-to-myometrium $(\mathrm{p}<0.001)$, and the presence of polypoid tumors $(\mathrm{p}=0.037)$ on MRI. ${ }^{31}$ In particular, false-positive cases were frequently found in the detection of any degree of myometrial invasion, and these results gives us attention in performing fertility-sparing treatment as the primary therapy of uterine corpus cancer. ${ }^{44}$

As a result, previous results for the prediction of LN metastasis and myometrial invasion are not sufficiently reliable, thus leaving room for further study. On the other hand, the risk of LN metastasis based on pathological findings, such as myometrial invasion and tumor grade in 834 Korean patients

Table 2. Performance of magnetic resonance imaging (MRI), positron emission tomography/computed tomography (PET/CT), and CA-125 in prediction of lymph node metastasis

\begin{tabular}{llcccccc}
\hline \multicolumn{1}{c}{ Author, year } & Modality & Cases (n) & Se (\%) & Sp (\%) & PPV (\%) & NPV (\%) & Accuracy (\%) \\
\hline Chung (2007) & MRI & 120 & 68.8 & 97.1 & 78.6 & 95.3 & 93.3 \\
Yoo $(2009)^{33}$ & MRI* & 99 & 77.7 & 85.6 & 35.0 & 94.7 & - \\
Han (2010) & MRI or CT & 297 & 53.3 & 92.9 & 45.7 & 94.7 & - \\
Cho (2010) & MRI & 166 & 45.0 & 80.8 & 24.3 & 91.4 & - \\
Park (2008) & MRI & 53 & 46.2 & 87.9 & 28.6 & 94.0 & 83.9 \\
${\text { Choi }(2005)^{35}}_{\text {Chung }(2006)^{37}}^{35}$ & PET/CT & 53 & 69.2 & 90.3 & 42.9 & 96.6 & 88.3 \\
Han $(2010)^{34}$ & CA-125 & 42 & 100 & 87.2 & 37.5 & 100 & - \\
\hline
\end{tabular}

Se: sensitivity, Sp: specificity, PPV: positive predictive value, NPV: negative predictive value.

${ }^{*}$ Only pelvic nodes were included. ${ }^{\dagger}$ The cut-off value was determined to be $50 \mathrm{U} / \mathrm{mL}$. ${ }^{\ddagger}$ The cut-off value was determined to be $28.5 \mathrm{U} / \mathrm{mL}$.

${ }^{s}$ The cut-off value was determined to be $28 \mathrm{U} / \mathrm{mL}$ (if $\geq 50$ years of age) and $20 \mathrm{U} / \mathrm{mL}$ (if $\leq 49$ years of age).

Table 3. Performance of magnetic resonance imaging (MRI) in prediction of myometrial invasion

\begin{tabular}{|c|c|c|c|c|c|c|c|}
\hline Author, year & Modality & Cases (n) & Se $(\%)$ & Sp (\%) & PPV (\%) & NPV (\%) & Accuracy (\%) \\
\hline $\operatorname{Kim}(1995)^{41}$ & MRI & 26 & 90 & 88 & - & - & 89 \\
\hline Ahn $(2006)^{42}$ & MRI & 43 & 87.5 & 85.7 & 58.3 & 96.8 & - \\
\hline Chung $(2007)^{31}$ & MRI & $120^{*}$ & 50.6 & 89.2 & 91.3 & 44.6 & 62.5 \\
\hline Yoo $(2009)^{33}$ & MRI & 99 & 46.6 & 84.5 & 35 & 89.8 & - \\
\hline Hwang (2009) ${ }^{43}$ & MRI & 53 & 50.0 & 89.7 & 63.6 & 83.3 & 79.2 \\
\hline \multirow[t]{2}{*}{ Suh $(2009)^{44}$} & MRI & $301^{*}$ & 68.8 & 74.4 & 86.9 & 49.2 & 59.2 \\
\hline & MRI & 301 & 55.9 & 92.4 & 50.0 & 93.9 & 88.0 \\
\hline Han $(2010)^{34}$ & MRI & 219 & 36.4 & 88.3 & 25.8 & 93.6 & - \\
\hline Cho $(2010)^{35}$ & MRI & 182 & 66.7 & 95.2 & 77.4 & 92.1 & - \\
\hline
\end{tabular}

Se: sensitivity, Sp: specificity, PPV: positive predictive value, NPV: negative predictive value.

*Both deep and superficial myometrial invasion was considered; others only included deep myometrial invasion. 
with endometrioid uterine cancers, were analyzed by Lee et al. ${ }^{30}$ Of the 215 patients with no myometrial invasion and tumor grade I/II, only 1 patient $(0.5 \%)$ had LN metastasis and the other patients had significant risk, that is, at least more than $3.5 \%$. Therefore, all uterine corpus cancers, except endometrioid uterine cancers with no myometrial invasion and tumor grade 1-2, would require complete pelvic and para-aortic lymphadenectomy for surgical staging.

\section{ROLE OF SYSTEMATIC LYMPHADENECTOMY}

Systematic lymphadenectomy has been reported to have an important role in the surgical staging of uterine corpus cancer. ${ }^{45}$ It is used as a prognostic indicator and suggests guidance for adjuvant treatment. Retrospective studies have reported that more extensive lymphadenectomy is associated with improved survival in patients with uterine corpus cancer, including high-risk, early-stage disease. ${ }^{13,46}$ However, the therapeutic value of systematic lymphadenectomy for stage I uterine cancer is not evident in all studies. Data from the Surveillance, Epidemiology, and End Results (SEER) program also showed that lymphadenectomy is associated with an improved disease-specific survival in stage I disease with tumor grade $3 .^{47}$ On the other hand, systematic lymphadenectomy was not recommended as a routine procedure for therapeutic purposes in patients with stage I disease in the A Study in the Treatment of Endometrial Cancer (ASTEC) trial. ${ }^{15}$ The negative results from this trial may be caused by the fact that all histologic subtypes were included, para-aortic LN dissection was optional and inconsistently harvested, an inadequate number of LNs was retrieved in $1 / 3$ of patients, and most patients were in the low-risk group. ${ }^{48,49}$

A Korean multi-center retrospective study involving 758 patients surgically treated for early-stage endometrioid uterine cancer, with a median follow-up of 35 months, reported that systematic lymphadenectomy did not provide a therapeutic benefit in terms of overall survival in all of the patients, while the systematic lymphadenectomy group showed improved overall survival in high-risk patients. ${ }^{50}$ In a retrospective analysis of 303 women with stage I disease, Seo et al. ${ }^{51}$ concluded that complete surgical staging, including lymphadenectomy, did not improve overall survival significantly. For non-endometrioid uterine cancer, 112 patients who underwent surgical staging were retrospectively reviewed. The systematic lymphadenectomy group did not have improved overall survival and distant failure was the prominent pattern of disease spread irrespective of systematic lymphadenectomy. ${ }^{50}$

To evaluate a therapeutic role for para-aortic lymphadenectomy, Chang et al. ${ }^{52}$ compared 85 women who underwent surgical staging with pelvic and para-aortic lymphadenectomy with 75 women who received surgical staging with pelvic lymphadenectomy alone in stage I-III uterine cancer. They proposed that patients who underwent para-aortic lymphadenectomy had improved 5-year disease-free survival and overall survival in patients with intermediate- and high-risk uterine cancer. However, a consensus has not been reached regarding the issue of whether to perform para-aortic lymphadenectomy on intermediate- and high-risk patients. ${ }^{53}$

Therefore, we suggest that systematic lymphadenectomy is effective in detecting micro or occult LN metastasis, and thus improve surgical staging, and make it possible to accurately predict the prognosis in patients with uterine corpus cancer.

\section{ROLE OF MINIMALLY INVASIVE SURGERY}

Since laparoscopy was first proposed as an option for apparently early-stage uterine corpus cancer in $1993,{ }^{54}$ several Korean researchers have published their experience on the feasibility of this approach (Table 4) ${ }^{55-58}$ These results collectively suggest that laparoscopic staging is as feasible and effective as laparotomy. Recently, the laparoscopic approach has been more commonly used in Korea. According to results of the Korean Gynecologic Oncology Group (KGOG) survey in $2009,^{59}$ laparoscopic staging was routinely performed by about one-half of Korean gynecologic oncologists. This trend was more common in young surgeons with 10 years of experience or less.

Cho et al. ${ }^{58}$ retrospectively analyzed 388 women with clinical stage I-II treated by laparoscopy or laparotomy between 1997 and 2006. Compared with laparotomy, the laparoscopy group had shorter hospital stays and fewer complications, and had no difference in operative time and number of harvested LNs. Nevertheless, most intra-operative complications, including injuries to the great vessels, bladder, ureters, and bowel serosa were more frequent in the laparoscopy group; most intra-operative complications were repaired by laparoscopic methods. Post-operative complications, such as wound problems, intra-abdominal abscesses, ileus, and thromboembolic events were more common in the laparotomy group. They found that the survival outcome and recurrence rate after laparoscopy was also similar to the laparotomy group (Table 5). In another retrospective study involving stage I-III disease, there was better survival in the laparoscopy group, but the results were limited because of favorable tumor characteristics in the laparoscopy group. ${ }^{56}$

Although laparoscopic staging has become an accepted alternative to traditional laparotomy, it has not been determined whether laparoscopic staging using a uterine manipulator is associated with positive peritoneal cytology or not. Regarding this issue, it has been suggested that laparoscopic staging using a uterine manipulator with a balloon might be associated with positive cytologic conversion. ${ }^{60}$ They showed that 2 of 46 patients had positive cytology conversion after the insertion of a uterine manipulator, but neither of the 2 women had recurrences.

On the other hand, robotic surgery using the da Vinci system (Intuitive Surgical Inc., Sunnyvale, CA, USA) has received attention as a new surgical option for the treatment of uterine 
Table 4. Feasibility of laparoscopy for the management of uterine corpus cancer

\begin{tabular}{|c|c|c|c|c|c|c|c|c|}
\hline \multirow{2}{*}{ Author, year } & \multirow{2}{*}{ Subjects (n) } & \multirow{2}{*}{ Stage } & \multicolumn{2}{|c|}{ No. harvested LNs } & \multicolumn{2}{|c|}{ Freq. of complications } & \multirow{2}{*}{$\begin{array}{l}\text { Operating } \\
\text { time (min) }\end{array}$} & \multirow{2}{*}{$\begin{array}{c}\text { Hospital } \\
\text { stay (days) }\end{array}$} \\
\hline & & & Pelvic & PA & IOC (\%) & POC (\%) & & \\
\hline \multicolumn{9}{|l|}{ Laparoscopy } \\
\hline Cho $(2007)^{58 *}$ & 165 & I-II & 26 & 5 & $6(3.6)$ & $10(6.1)$ & 155 & 10 \\
\hline Lee $(2008)^{57}$ & 35 & I-III & 22 & 7 & $1(2.9)$ & $3(8.6)$ & 150 & 8 \\
\hline Hahn $(2010)^{56}$ & 140 & I-III & 28 & 13 & NA & $23(16.4)$ & 160 & 10 \\
\hline Jung $(2010)^{55}$ & 25 & I & 18 & 4 & 0 & $2(8.0)$ & 165 & 8 \\
\hline \multicolumn{9}{|l|}{ Robotic surgery } \\
\hline Jung $(2010)^{55}$ & 28 & I & 21 & 8 & 0 & $2(7.1)$ & 193 & 8 \\
\hline
\end{tabular}

LNs: lymph nodes, PA: para-aortic, IOC: intra-operative complication, POC: post-operative complication, EBL: estimated blood loss, NA: not applicable.

*They used mean values and the others used median values.

Table 5. Survival outcomes of Korean studies comparing laparoscopy with laparotomy for the management of uterine corpus cancer

\begin{tabular}{|c|c|c|c|c|c|c|c|}
\hline \multirow{2}{*}{ Author, year } & \multirow{2}{*}{ Study period } & \multirow{2}{*}{ Stage } & \multicolumn{2}{|c|}{ No. subjects } & \multicolumn{2}{|c|}{ Follow-up periods (mo) } & \multirow{2}{*}{ Survival outcome } \\
\hline & & & Laparoscopy & Laparotomy & Laparoscopy & Laparotomy & \\
\hline Cho $(2007)^{58}$ & $1997-2006$ & I-II & 165 & 144 & $28(1-98)$ & $51(1-113)$ & PFS, $95.5 \%$ vs. $96.5 \%$ \\
\hline Hahn $(2010)^{56}$ & $1996-2007$ & I-III & 140 & 325 & $40(1-145)$ & $67(1-149)$ & DFS, $97.7 \%$ vs. $90.8 \%$ \\
\hline
\end{tabular}

PFS: progression-free survival, DFS: disease-free survival.

corpus cancer. Robotic surgery has been proposed as an innovative technology that uses a three-dimensional visual system and laparoscopic instruments with wrist-like mechanisms. The feasibility of robotic surgery was investigated by one Korean comparative study. ${ }^{55}$ They described that robotic surgery using three robotic arms is a feasible approach for the uterine corpus cancer because both the robotic surgery and laparoscopy groups had a similar number of harvested LNs, operative times, complications, and hospital stays.

\section{ROLE OF OVARIAN-SAVING SURGERY}

The incidence of ovarian metastasis in patients with uterine corpus cancer has been reported to be approximately $5 \%$, and more infrequent in early-stage disease. ${ }^{40,61}$ Early-stage, welldifferentiated uterine corpus cancer has been reported to be most commonly encountered in younger patients. Even though bilateral salpingo-oophorectomy is recommended as a part of surgical staging for the treatment of uterine corpus cancer, the issue of ovarian-saving surgery for early-stage uterine corpus cancer needs further consideration. ${ }^{59,62}$ In two case-control Korean studies regarding this issue, it was concluded that ovarian-saving surgery in early-stage disease did not affect disease-free survival and overall survival with a mean of 39 months follow-up ${ }^{63}$ and recurrence. ${ }^{64}$ They suggested young patients with a low pre-operative CA-125 and low tumor grade are considered as candidates for ovarian-saving surgery. ${ }^{64}$

In a nationwide survey under the influence of the Korean Gynecologic Oncology Group, Lee et al. ${ }^{48}$ analyzed outcomes of 175 women undergoing ovarian-saving surgery. During a median follow-up of 55 months, recurrence-free survival and overall survival were $94.3 \%$ and $93.3 \%$, respectively. All 7 recurrent cases had risk factors, including non-endometrioid histology (4/7), deep myometrial invasion (5/7), cervical stromal invasion (4/7), and inadequate adjuvant treatment (4/7). They proposed the indications of ovarian-saving surgery for uterine corpus cancer to be as follows: women who desire to retain ovarian function; no gross intra-operative extra-uterine spread; no gross abnormalities in bilateral ovaries, negative results of frozen biopsy for lymph nodes suspicious for metastasis; endometrioid-type histology on pre-operative biopsy; and women without a genetic predisposition to breast or ovarian cancer.

\section{ROLE OF ADJUVANT THERAPY}

Whereas adjuvant treatment in advanced-stage uterine corpus cancer is commonly accepted, the role of adjuvant radiation in early-stage uterine cancer is a matter of debate. Most trials have been able to show the same trend of adjuvant radiation to reduce locoregional recurrence, but have not been able to convert these results into improvement in overall survival. ${ }^{16,65-67}$ In an aforementioned Korean study involving 758 patients for early-stage endometrioid uterine cancer, the effect of adjuvant radiation on overall survival in 547 endometrioid uterine cancer patients who underwent systematic lymphadenectomy was analyzed. ${ }^{50}$ The 5 -year survival rate of the adjuvant radiation versus the no-adjuvant radiation group was similar and this result was repeated, even in the high-risk group. Therefore, it is 
thought that adjuvant radiation is of limited value in controlling distant recurrences of uterine corpus cancer, ${ }^{68}$ especially in systematic lymphadenectomized patients. In view of the limited value of adjuvant radiation in systematic lymphadenectomized patients, the role of adjuvant radiation should be re-evaluated based on the recurrence risk and disease spread pattern for early-stage endometrioid uterine cancer.

On the other hand, adjuvant chemotherapy or chemoradiation may be proposed as a reasonable option in these high-risk patients. ${ }^{69,70}$ There have been two Korean studies involving this issue. $^{71,72}$ In an analysis of 46 patients with high- risk early disease, the adjuvant chemoradiation or chemotherapy group showed better disease-free survival than the adjuvant radiation group. ${ }^{71}$ Another study for stage I-IV disease suggested that adjuvant paclitaxel/platinum chemotherapy had a similar activity as adjuvant radiation and acceptable toxicity for the treatment of uterine corpus cancer. ${ }^{72}$

\section{ROLE OF FERTILITY-SPARING TREATMENT}

Since it has been proposed that young women (under 40 years of age) with endometrioid uterine cancer may be treated conservatively with progestin therapy ${ }^{73,74}$ a few Korean studies have supported this hypothesis. ${ }^{75-78}$ Recently, Hahn et al. ${ }^{77}$ demonstrated the efficacy of progestin therapy in early-stage, grade 1 endometrioid uterine cancer. They found that the efficacy of 250-1500 mg of medroxyprogesterone acetate (MPA) or $160 \mathrm{mg}$ of megestrol for grade 1 endometrioid uterine cancer (35 cases) presumed to be stage IA was complete remission (CR) in 22 women (63\%). However, 9 of the 22 patients (41\%) with CR developed recurrent disease and the median time-torecurrence was 12 months (range, 8 to 48 months). This result was comparable with one phase II trial by Ushijima et al. ${ }^{74}$ showing $55 \% \mathrm{CR}$ and $47 \%$ recurrence after CR. Thus, in spite of the proven efficacy of fertility-sparing treatment with high-dose of MPA, close follow-up is needed because of the substantial rate of recurrence, even in responders. For pregnancy outcomes, fertility-preserving therapy is considered a good option in women with early-stage uterine corpus cancer.
According to two retrospective Korean studies, approximately $80 \%$ of women who tried to conceive were successful with normal pregnancies, and 8 of 14 pregnancies resulted in live births. $^{77,78}$

\section{POSITRON EMISSION TOMOGRAPHY/COMPUTED TOMOGRAPHY (PET/CT)}

Recently, investigative work involving molecular imaging technologies has received much attention. PET uses the glucose analogue, 18-fluorodeoxyglucose (FDG), as a radioisotope and relies on increased metabolism of tumor cells, and thus increased glucose uptake. ${ }^{79} \mathrm{PET} / \mathrm{CT}$ provides the synergistic benefits of morphologic and molecular imaging because of localization of increased FDG uptake with anatomical specificity. ${ }^{80}$ Substantial evidence has now emerged documenting the role of PET/CT in the management of uterine corpus cancer patients, at the pre-operative evaluation as well as at the posttreatment surveillance (Table 6)..$^{32,80,81}$ Park et al. ${ }^{32}$ performed a retrospective comparison of surgical staging with PET/CT in 53 uterine corpus cancer patients. They showed that pre-operatively, PET/CT detected lymph node metastasis with $69 \%$ sensitivity and $90 \%$ specificity. According to other studies for the detection of recurrent disease, ${ }^{80,81}$ PET/CT had excellent performance with $100 \%$ sensitivity and $83-100 \%$ specificity. The use of PET/CT has been shown to detect recurrences even in asymptomatic women with $100 \%$ sensitivity and specificity, and can provide important prognostic information for women after primary treatment.

\section{PROGNOSTIC FACTORS}

The prognostic impact of age, histologic subtype, grade, and FIGO stage has been established in Western populations. ${ }^{82}$ However, according to a recent retrospective survey, uterine corpus cancer of Korean women is characterized by a younger age in peak incidence and less obesity compared to Western countries. ${ }^{19}$ Thus, the prognostic significance of the aforementioned factors in Korean patients with endometrioid ute-

Table 6. Performance of positron emission tomography/computed tomography (PET/CT) and PET for the evaluation of uterine corpus cancer

\begin{tabular}{|c|c|c|c|c|c|c|c|c|}
\hline \multirow{2}{*}{ Author, year } & \multirow{2}{*}{ Modality } & \multirow{2}{*}{$\begin{array}{c}\text { No. of } \\
\text { patients }\end{array}$} & \multirow{2}{*}{ Validity } & $\mathrm{Se}$ & $\mathrm{Sp}$ & PPV & NPV & Accuracy \\
\hline & & & & \multicolumn{5}{|c|}{ (\%) } \\
\hline \multirow[t]{4}{*}{ Park $(2008)^{32}$} & $\mathrm{PET} / \mathrm{CT}$ & 53 & Primary lesion & 90 & 51 & 93 & 38 & 85 \\
\hline & & & PALNM & 57 & 88 & 57 & 88 & 81 \\
\hline & & & PLNM & 83 & 91 & 36 & 99 & 88 \\
\hline & & & Total LNM & 69 & 90 & 43 & 97 & 88 \\
\hline Chung $(2008)^{80}$ & $\mathrm{PET} / \mathrm{CT}$ & 31 & Recurrent lesion & 100 & 95 & 92 & 100 & 97 \\
\hline \multirow[t]{2}{*}{ Park $(2008)^{81}$} & $\mathrm{PET} / \mathrm{CT}$ or PET & $24^{*}$ & Recurrent lesion & 100 & 83 & 96 & 95 & 100 \\
\hline & & $64^{\dagger}$ & Recurrent lesion & 100 & 100 & 100 & 100 & 100 \\
\hline
\end{tabular}

Se: sensitivity, Sp: specificity, PPV: positive predictive value, NPV: negative predictive value, PALNM: para-aortic lymph node metastasis, PLNM: pelvic lymph node metastasis, LNM: lymph node metastasis.

${ }^{*}$ Patients were suspected to have recurrence based on tumor markers or CT. ${ }^{\dagger}$ Patients were asymptomatic with no evidence of recurrence. 
rine cancer is different. For example, FIGO stage (hazard ratios, 3.37; $\mathrm{p}<0.01$ ) and lymphovascular invasion (hazard ratios, 2.75; $\mathrm{p}=0.01$ ) were significant prognostic factors for overall survival, whereas age provided no significant impact in prognostic ability (Table 7). Even though age is well-known as one of the prognostic factors for uterine corpus cancer, this result did not show independent prognostic ability. This result may reflect the original characteristics of Korean women, i.e., Korean patients were younger compared to Western patients. Therefore, the prognostic effect of age could be lessened.

To further improve treatment and follow-up for uterine corpus cancers, a number of molecular markers have been extensively studied. DNA ploidy, hormone receptors, p53, bcl-2, and proliferation markers have already been shown with consistent results to be prognostic factors through retro- spective studies. ${ }^{82}$ In Korea, there have been several efforts to define the molecular factors for uterine corpus cancer (Table 8). ${ }^{37,83-88}$ Whereas cyclooxygenase-2 (COX-2), mammalian target of rapamycin (mTOR), and microsatellite instability (MSI) have shown no prognostic ability, several other markers, including p53, pre-operative CA-125, and osteopontin, have been shown to have significance as prognostic factors for uterine corpus cancers.

Immunohistochemical overexpression of p53, one of the most frequently detected tumor suppressor genes in human cancer, has a strong association with tumor aggressiveness. ${ }^{83}$ Similarly, based on the results of 131 patients, $29.8 \%$ of patients had p53 alteration determined by p53 overexpression or exonal mutation, and p53 alteration was associated not only with aggressive tumor behavior, but with poor disease-free survival. ${ }^{86}$

Table 7. Hazard ratios of endometrioid uterine cancer based on clinico-pathological variables in Korea

\begin{tabular}{|c|c|c|c|c|c|c|}
\hline \multirow{2}{*}{ Variables } & & & \multicolumn{2}{|c|}{ Univariate } & \multicolumn{2}{|c|}{ Multivariate } \\
\hline & & & HR $(95 \%$ CI $)$ & p-value & HR (95\% CI) & $\mathrm{p}$-value \\
\hline \multirow[t]{3}{*}{ BMI } & $<23.0$ & 297 & 1.00 & & 1.00 & \\
\hline & $23.0-24.9$ & 207 & $0.98(0.42-2.27)$ & 0.96 & $0.93(0.37-2.30)$ & 0.87 \\
\hline & $\geq 25.0$ & 433 & $0.82(0.40-1.66)$ & 0.58 & $0.87(0.41-1.83)$ & 0.70 \\
\hline \multirow[t]{2}{*}{ Age } & $\leq 50$ & 376 & 1.00 & & 1.00 & \\
\hline & $>50$ & 561 & $5.14(2.01-13.11)$ & $<0.01$ & $2.66(0.84-8.50)$ & 0.10 \\
\hline \multirow[t]{2}{*}{ Menopause } & No & 396 & 1.00 & & 1.00 & \\
\hline & Yes & 505 & $3.08(1.41-6.73)$ & $<0.01$ & $1.51(0.57-3.99)$ & 0.41 \\
\hline \multirow[t]{2}{*}{ Stage } & $\mathrm{I}+\mathrm{II}$ & 777 & 1.00 & & 1.00 & \\
\hline & $\mathrm{III}+\mathrm{IV}$ & 142 & $6.50(3.50-12.09)$ & $<0.01$ & $3.37(1.55-7.35)$ & $<0.01$ \\
\hline \multirow[t]{2}{*}{ ADJTX } & No & 590 & 1.00 & & 1.00 & \\
\hline & Yes & 340 & $4.30(2.22-8.34)$ & $<0.01$ & $1.30(0.53-3.22)$ & 0.57 \\
\hline \multirow[t]{3}{*}{ Grade } & I & 644 & 1.00 & & 1.00 & \\
\hline & II & 199 & $2.20(1.06-4.55)$ & 0.03 & $1.46(0.65-3.24)$ & 0.36 \\
\hline & III & 81 & $4.50(1.92-10.57)$ & $<0.01$ & $1.96(0.79-4.88)$ & 0.15 \\
\hline \multirow[t]{2}{*}{ LNM } & No & 629 & 1.00 & & & \\
\hline & Yes & 80 & $6.30(2.93-13.53)$ & $<0.01$ & & \\
\hline \multirow[t]{2}{*}{$\mathrm{TD}$} & $\leq 2 \mathrm{~cm}$ & 299 & 1.00 & & & \\
\hline & $>2 \mathrm{~cm}$ & 485 & $2.02(0.94-4.36)$ & 0.07 & & \\
\hline \multirow[t]{2}{*}{ MI } & No & 273 & 1.00 & & & \\
\hline & Yes & 639 & $3.81(1.49-9.73)$ & 0.01 & & \\
\hline \multirow[t]{2}{*}{$\mathrm{CE}$} & No & 816 & 1.00 & & & \\
\hline & Yes & 107 & $3.05(1.49-6.24)$ & $<0.01$ & & \\
\hline \multirow[t]{2}{*}{ LVSI } & No & 734 & 1.00 & & 1.00 & \\
\hline & Yes & 184 & $5.86(3.11-11.0)$ & $<0.01$ & $2.75(1.27-5.95)$ & 0.01 \\
\hline \multirow[t]{2}{*}{$\mathrm{AE}$} & No & 840 & 1.00 & & & \\
\hline & Yes & 53 & $5.80(2.74-12.26)$ & $<0.01$ & & \\
\hline \multirow[t]{2}{*}{ PPC } & No & 836 & 1.00 & & & \\
\hline & Yes & 39 & $4.54(1.89-10.91)$ & $<0.01$ & & \\
\hline \multirow[t]{4}{*}{ RS } & $\mathrm{ER}-/ \mathrm{PR}-$ & 91 & 1.00 & & & \\
\hline & $\mathrm{ER}+/ \mathrm{PR}-$ & 30 & $0.60(0.07-5.13)$ & 0.64 & & \\
\hline & $\mathrm{ER}-/ \mathrm{PR}+$ & 63 & $0.38(0.07-1.99)$ & 0.25 & & \\
\hline & $\mathrm{ER}+/ \mathrm{PR}+$ & 213 & $0.68(0.23-2.00)$ & 0.49 & & \\
\hline
\end{tabular}

HR: hazard ratio, CI: confidence interval, BMI: body mass index, ADJTX: adjuvant treatment, LNM: lymph node metastasis, TD: tumor diameter, MI: myometrial invasion, CE: cervical extension, LVSI: lympho-vascular space invasion, AE: adnexal involvement, PPC: positive peritoneal cytology, RS: receptor status, ER: estrogen receptor, PR: progesterone receptor. 
Table 8. Molecular prognosticators for uterine corpus cancer in Korea

\begin{tabular}{|c|c|c|c|c|c|c|c|}
\hline $\begin{array}{l}\text { Author, } \\
\text { year }\end{array}$ & Target & Cases & Materials & Tool & Results & Outcome & $\begin{array}{l}\text { Prognostic } \\
\text { ability }\end{array}$ \\
\hline \multirow[t]{2}{*}{$\begin{array}{l}\text { Jeon } \\
(2004)^{83}\end{array}$} & COX-2 & 152 & $\begin{array}{l}\text { Paraffin-embedded } \\
\text { tissue }\end{array}$ & $\mathrm{IHC}$ & $\begin{array}{l}17.8 \% \text { of patients were COX- } \\
2 \text { positive }\end{array}$ & $\begin{array}{l}\text { Possible association with } \\
\text { carcinogenesis during the } \\
\text { postmenopausal period }\end{array}$ & Null \\
\hline & p53 & 152 & $\begin{array}{l}\text { Paraffin-embedded } \\
\text { tissue }\end{array}$ & IHC & $\begin{array}{l}20.4 \% \text { of patients showed } \\
\text { overexpression }\end{array}$ & $\begin{array}{l}\text { Strong association with can- } \\
\text { cer aggressiveness }\end{array}$ & Null \\
\hline $\begin{array}{l}\text { Chung } \\
(2006)^{37}\end{array}$ & CA-125 & 92 & Serum & RIA & $\begin{array}{l}\text { DFS of patients with } \leq 28.5 \\
\mathrm{IU} / \mathrm{mL} \text { was worse prog- } \\
\text { nosis than patients with }> \\
28.5 \mathrm{IU} / \mathrm{mL}\end{array}$ & $\begin{array}{l}\text { Independent prognostic mar- } \\
\text { ker for DFS }\end{array}$ & $\begin{array}{l}\text { DFS, log rank; } \\
\mathrm{p}=0.004\end{array}$ \\
\hline $\begin{array}{l}\text { An } \\
(2007)^{87}\end{array}$ & MSI & 100 & $\begin{array}{l}\text { Paraffin-embedded } \\
\text { tissue }\end{array}$ & TMA & $\begin{array}{l}\text { MSI-high phenotype was re- } \\
\text { lated with LVSI, DMI, and } \\
\text { higher clinical stages }\end{array}$ & $\begin{array}{l}\text { Possible role as a prognostic } \\
\text { factor }\end{array}$ & Null \\
\hline $\begin{array}{l}\text { Kim } \\
(2008)^{88}\end{array}$ & PTTG & 43 & $\begin{array}{l}\text { Paraffin-embedded } \\
\text { tissue }\end{array}$ & IHC & $\begin{array}{l}7.5 \% \text { of patients had nuclear } \\
\text { PTTG overexpression with } \\
\text { a lower OS }\end{array}$ & $\begin{array}{l}\text { Possible role as a prognostic } \\
\text { factor }\end{array}$ & $\begin{array}{l}\text { OS, log-rank; } \\
\mathrm{p}=0.04\end{array}$ \\
\hline $\begin{array}{l}\text { Cho } \\
(2009)^{85}\end{array}$ & Osteopontin & 56 & $\begin{array}{l}\text { Frozen tissue, } \\
\text { paraffin-embedded } \\
\text { tissue, plasma }\end{array}$ & $\begin{array}{l}\text { Real-time } \\
\text { PCR, IHC, } \\
\text { ELISA }\end{array}$ & $\begin{array}{l}62.1 \% \text { of stage I patients } \\
\text { were seropositive that were } \\
\text { not detected by CA125; } \\
\text { AUC } 0.758 \text { for plasma os- } \\
\text { teopontin levels }\end{array}$ & $\begin{array}{l}\text { Useful diagnostic marker for } \\
\text { uterine cancer, independent } \\
\text { prognostic marker for DFS }\end{array}$ & $\begin{array}{l}\text { DFS, } H R=3.18 \\
\mathrm{p}=0.0035\end{array}$ \\
\hline $\begin{array}{l}\text { No } \\
(2009)^{84}\end{array}$ & mTOR & 141 & $\begin{array}{l}\text { Paraffin-embedded } \\
\text { tissue }\end{array}$ & $\mathrm{IHC}$ & $\begin{array}{l}7.1 \% \text { of patients showed } \\
\text { overexpression }\end{array}$ & $\begin{array}{l}\text { Association with COX-2 } \\
\text { overexpression }\end{array}$ & Null \\
\hline $\begin{array}{l}\text { Lee } \\
(2010)^{86}\end{array}$ & p53 & 131 & $\begin{array}{l}\text { Paraffin-embedded } \\
\text { tissue }\end{array}$ & PCR, IHC & $\begin{array}{c}29.8 \% \text { of patients had p } 53 \text { al- } \\
\text { teration with a lower DFS }\end{array}$ & $\begin{array}{l}\text { Independent prognostic mar- } \\
\text { ker for DFS }\end{array}$ & $\begin{array}{l}\text { DFS, } H R=17.7 \\
p=0.027\end{array}$ \\
\hline
\end{tabular}

COX-2: cyclooxygenase-2, IHC: immunohistochemistry, RIA: radioimmunoassay, DFS: disease-free survival, MSI: microsatellite instability, TMA: tissue microarray, LVSI: lympho-vascular space invasion, DMI: deep myometrial invasion, PTTG: pituitary tumor-transforming gene, OS: overall survival, PCR: polymerase chain reaction, ELISA: enzyme-linked immunosorbent assay, HR: hazard ratio, mTOR: mammalian target of rapamycin.

Preoperative serum CA-125 has been shown to be a significant prognostic factor. ${ }^{89}$ According to Chung et al., ${ }^{37}$ patients with a serum CA- $125 \leq 28.5 \mathrm{U} / \mathrm{mL}$ have a significantly better 5-year disease-free survival than patients with a CA- $125>28.5 \mathrm{U} / \mathrm{mL}$ (85.6\% vs. $60.0 \%$, $\mathrm{p}=0.004)$. Therefore, they suggested a preoperative CA-125 as a useful tool for optimal individualized cancer treatment.

Osteopontin, a kind of phosphoglycoprotein, is known as a mediator of tumor transformation and malignant progression in human cancers, and its overexpression in tissues or blood of cancer patients may indicate the presence of a tumor. ${ }^{90} \mathrm{Cho}$ et al. ${ }^{85}$ investigated the diagnostic and prognostic role of osteopontin in uterine corpus cancer. They proved that osteopontin was seropositive in $62.1 \%$ of patients with stage I disease who were not detected by CA-125, and that osteopontin positivity was an independent prognosticator for disease-free survival in patients with uterine corpus cancer.

\section{MANAGEMENT OF RECURRENT DISEASE}

Most uterine corpus cancers are diagnosed at an early stage and have a favorable prognosis. However, a substantial number of patients undergo disease recurrence after primary treatment. According to one Korean retrospective study of 301 pa- tients, ${ }^{91}$ approximately 26 (9\%) of patients develop recurrent disease and the mean time-to-recurrence is 29 months. Among women with recurrences, $22(85 \%)$ had distant failure and most women with recurrences presented at an advanced stage at the time of diagnosis. After diagnosing a recurrence, 18 women received systemic chemotherapy or chemoradiation, 2 women had radiation, and only one woman underwent surgical treatment. Among the 18 women with chemotherapy, the taxane-based group had a better median survival than the non-taxane group ( 22 vs. 15 months, $\mathrm{p}=0.047) .{ }^{92}$ In the planning for patients with recurrent disease, it is important to consider the site of recurrence, performance status of the patient, and prior therapy the patient has received. After specific considerations for each patient, combined modalities, as well as surgical cytoreduction, radiation therapy, hormonal treatment, systemic chemotherapy, and palliative therapy may be used. In this era, research should focus on developing new chemotherapeutic and molecular targets active against uterine corpus cancer.

\section{HORMONE REPLACEMENT THERAPY}

Because there has been no conclusive data to prove the benefit or safety of hormone replacement therapy in patients with 
uterine corpus cancer, this question remains unanswered. To date, an overall lower recurrence rate or a non-significant difference in recurrence between hormone-users and -non-users has been noted in several retrospective studies ${ }^{93-96}$ and in one randomized controlled trial. ${ }^{97}$ A retrospective Korean study which evaluated tibolone in patients with uterine corpus cancer also showed no significant difference in disease-free survival and overall survival between the two groups. ${ }^{98}$ This finding should be used along with other information for counseling patients regarding the risks of hormone replacement therapy in uterine corpus cancer.

\section{CONCLUSION}

Like other malignancies, uterine corpus cancer must be affected by genetic differences. Thus, if possible, treatment guidelines should be individualized based on ethnic-specific treatment results. Even though there have been a number of advances in treatment strategies and research products for uterine corpus cancers in Korea, most of our data are characterized by retrospective design, small sample size, single institute experience, and insufficient follow-up. Thus, prospective multi-center trials should be performed to make more progress in the treatment of gynecologic cancer patients, including uterine corpus cancer. In addition, we also should be interested in primary and secondary prevention to improve cancer control, and in treatment-related symptom management, palliation, and end-of-life care to improve quality of life.

\section{CONFLICT OF INTEREST}

No potential conflict of interest relevant to this article was reported.

\section{ACKNOWLEDGEMENTS}

This research was supported by the Kyung Hee University Research Fund in 2010 (KHU-20100651).

\section{REFERENCES}

1. Parkin DM, Pisani P, Ferlay J. Estimates of the worldwide incidence of 25 major cancers in 1990. Int J Cancer 1999; 80: 827-41.

2. SOG Gynecologic Oncology Committee. Annual report of gynecologic cancer registry program in Korea for 2004 (Jan. 1st, 2004-Dec. 31st, 2004). Korean J Obstet Gynecol 2007; 50: 28-78.

3. Sankaranarayanan R, Ferlay J. Worldwide burden of gynaecological cancer: the size of the problem. Best Pract Res Clin Obstet Gynaecol 2006; 20: 207-25.

4. Kaaks R, Lukanova A, Kurzer MS. Obesity, endogenous hormones, and endometrial cancer risk: a synthetic review. Cancer Epidemiol Biomarkers Prev 2002; 11: 1531-43.

5. Lindemann K, Vatten LJ, Ellstrom-Engh M, Eskild A. Body mass, diabetes and smoking, and endometrial cancer risk: a follow-up study. Br J Cancer 2008; 98: 1582-5.
6. Bjorge T, Engeland A, Tretli S, Weiderpass E. Body size in relation to cancer of the uterine corpus in 1 million Norwegian women. Int J Cancer 2007; 120: 378-83.

7. Furberg AS, Thune I. Metabolic abnormalities (hypertension, hyperglycemia and overweight), lifestyle (high energy intake and physical inactivity) and endometrial cancer risk in a Norwegian cohort. Int J Cancer 2003; 104: 669-76.

8. Goodman MT, Hankin JH, Wilkens LR, Lyu LC, McDuffie K, Liu LQ, et al. Diet, body size, physical activity, and the risk of endometrial cancer. Cancer Res 1997; 57: 5077-85.

9. Jung KW, Won YJ, Park S, Kong HJ, Sung J, Shin HR, et al. Cancer statistics in Korea: incidence, mortality and survival in 2005. J Korean Med Sci 2009; 24: 995-1003.

10. ACOG practice bulletin, clinical management guidelines for obstetrician-gynecologists, number 65, August 2005: management of endometrial cancer. Obstet Gynecol 2005; 106: 413-25.

11. Pecorelli S. Revised FIGO staging for carcinoma of the vulva, cervix, and endometrium. Int J Gynaecol Obstet 2009; 105: 103-4.

12. Mohan DS, Samuels MA, Selim MA, Shalodi AD, Ellis RJ, Samuels JR, et al. Long-term outcomes of therapeutic pelvic lymphadenectomy for stage I endometrial adenocarcinoma. Gynecol Oncol 1998; 70: 165-71.

13. Cragun JM, Havrilesky LJ, Calingaert B, Synan I, Secord AA, Soper JT, et al. Retrospective analysis of selective lymphadenectomy in apparent early-stage endometrial cancer. J Clin Oncol 2005; 23: 3668-75.

14. Benedetti Panici P, Basile S, Maneschi F, Alberto Lissoni A, Signorelli M, Scambia G, et al. Systematic pelvic lymphadenectomy vs. no lymphadenectomy in early-stage endometrial carcinoma: randomized clinical trial. J Natl Cancer Inst 2008; 100: 1707-16.

15. Kitchener H, Swart AM, Qian Q, Amos C, Parmar MK. Efficacy of systematic pelvic lymphadenectomy in endometrial cancer (MRC ASTEC trial): a randomised study. Lancet 2009; 373: 125-36.

16. Creutzberg CL, van Putten WL, Koper PC, Lybeert ML, Jobsen JJ, Warlam-Rodenhuis CC, et al. Surgery and postoperative radiotherapy versus surgery alone for patients with stage-1 endometrial carcinoma: multicentre randomised trial. PORTEC Study Group. Post Operative Radiation Therapy in Endometrial Carcinoma. Lancet 2000; 355: 1404-11.

17. Blake P, Swart AM, Orton J, Kitchener H, Whelan T, Lukka H, et al. Adjuvant external beam radiotherapy in the treatment of endometrial cancer (MRC ASTEC and NCIC CTG EN.5 randomised trials): pooled trial results, systematic review, and meta-analysis. Lancet 2009; 373: 137-46.

18. Henderson BE, Feigelson HS. Hormonal carcinogenesis. Carcinogenesis 2000; 21: 427-33.

19. Jeong NH, Lee JM, Lee JK, Kim JW, Cho CH, Kim SM, et al. Role of body mass index as a risk and prognostic factor of endometrioid uterine cancer in Korean women. Gynecol Oncol 2010; 118: 24-8.

20. Xu WH, Dai Q, Xiang YB, Zhao GM, Ruan ZX, Cheng JR, et al. Nutritional factors in relation to endometrial cancer: a report from a population-based case-control study in Shanghai, China. Int J Cancer 2007; 120: 1776-81.

21. McCann SE, Freudenheim JL, Marshall JR, Brasure JR, Swanson MK, Graham S. Diet in the epidemiology of endometrial cancer in western New York (United States). Cancer Causes Control 2000; 11: 965-74.

22. Jeong NH, Song ES, Lee JM, Lee KB, Kim MK, Yun YM, et al. Preoperative levels of plasma micronutrients are related to endometrial cancer risk. Acta Obstet Gynecol Scand 2009; 88: 434-9. 
23. Lee KH, Lee JK, Kim JH, Lee JM, Song ES, Kim MK. Folic acid and vitamin B12 intake in relation to risk of endometrial cancer: case-control study. Korean J Obstet Gynecol 2008; 51: 1103-11.

24. Meyer LA, Westin SN, Lu KH, Milam MR. Genetic polymorphisms and endometrial cancer risk. Expert Rev Anticancer Ther 2008; 8: 1159-67.

25. Lee JM, Lee JH, Tong SY, Ki KD, Lee SK, Huh CY. The effect of HER-2 polymorphism according to age on the risk and pathologic feature of endometrial cancer. Korean J Obstet Gynecol 2009; 52: 529-37.

26. Roh JW, Kim JW, Park NH, Song YS, Park IA, Park SY, et al. p53 and p21 genetic polymorphisms and susceptibility to endometrial cancer. Gynecol Oncol 2004; 93: 499-505.

27. Kang S, Kim JW, Park NH, Song YS, Kang SB, Lee HP. Cyclin D1 polymorphism and the risk of endometrial cancer. Gynecol Oncol 2005; 97: 431-5.

28. Jo H, Kang S, Kim SI, Kim JW, Park NH, Song YS, et al. The C19007T polymorphism of ERCC1 and its correlation with the risk of epithelial ovarian and endometrial cancer in Korean womenL a case control study. Gynecol Obstet Invest 2007; 64: 84-8.

29. Tong SY, Ha SY, Ki KD, Lee JM, Lee SK, Lee KB, et al. The effects of obesity and HER-2 polymorphisms as risk factors for endometrial cancer in Korean women. BJOG 2009; 116: 1046-52.

30. Lee KB, Ki KD, Lee JM, Lee JK, Kim JW, Cho CH, et al. The risk of lymph node metastasis based on myometrial invasion and tumor grade in endometrioid uterine cancers: a multicenter, retrospective Korean study. Ann Surg Oncol 2009; 16: 2882-7.

31. Chung HH, Kang SB, Cho JY, Kim JW, Park NH, Song YS, et al. Accuracy of MR imaging for the prediction of myometrial invasion of endometrial carcinoma. Gynecol Oncol 2007; 104: 654-9.

32. Park JY, Kim EN, Kim DY, Suh DS, Kim JH, Kim YM, et al. Comparison of the validity of magnetic resonance imaging and positron emission tomography/computed tomography in the preoperative evaluation of patients with uterine corpus cancer. Gynecol Oncol 2008; 108: 486-92.

33. Yoo SC, Kim WY, Yoon JH, Kim HY, Lee EJ, Chang SJ, et al. Accuracy of preoperative magnetic resonance imaging in assessing lymph node metastasis and myometrial invasion in patients with uterine cancer. Eur J Gynaecol Oncol 2009; 30: 167-70.

34. Han SS, Lee SH, Kim DH, Kim JW, Park NH, Kang SB, et al. Evaluation of preoperative criteria used to predict lymph node metastasis in endometrial cancer. Acta Obstet Gynecol Scand 2010; 89: 168-74.

35. Cho H, Kim YT, Kim JH. Accuracy of preoperative tests in clinical stage I endometrial cancer: the importance of lymphadenectomy. Acta Obstet Gynecol Scand 2010; 89: 175-81.

36. Choi YS, Koh SB, Ahn JY, Yi CM, Shin IH, Lee TS. Usefulness of preoperative CA 125 level in decision making of lymphadenectomy in endometrial cancer patients. Korean J Obstet Gynecol 2005; 48: 2877-87.

37. Chung HH, Kim JW, Park NH, Song YS, Kang SB, Lee HP. Use of preoperative serum CA-125 levels for prediction of lymph node metastasis and prognosis in endometrial cancer. Acta Obstet Gynecol Scand 2006; 85: 1501-5.

38. Selman TJ, Mann CH, Zamora J, Khan KS. A systematic review of tests for lymph node status in primary endometrial cancer. BMC Womens Health 2008; 8: 8.

39. Girardi F, Petru E, Heydarfadai M, Haas J, Winter R. Pelvic lymphadenectomy in the surgical treatment of endometrial cancer.
Gynecol Oncol 1993; 49: 177-80.

40. Creasman WT, Morrow CP, Bundy BN, Homesley HD, Graham JE, Heller PB. Surgical pathologic spread patterns of endometrial cancer: a Gynecologic Oncology Group Study. Cancer 1987; 60: 2035-41.

41. Kim SH, Kim HD, Song YS, Kang SB, Lee HP. Detection of deep myometrial invasion in endometrial carcinoma: comparison of transvaginal ultrasound, CT, and MRI. J Comput Assist Tomogr 1995; 19: 766-72.

42. Ahn JY, Yi CM, Lee TS, Koh SB, Park YC, Jung KJ, et al. Analysis of factors to affect on MR assessment of myometrial invasion and cervical involvement in endometrial cancer. Korean J Obstet Gynecol 2006; 49: 113-21.

43. Hwang JH, Lee NW, Lee KW, Lee JK. Magnetic resonance imaging for assessment of deep endometrial invasion for patients with endometrial carcinoma. Aust N Z J Obstet Gynaecol 2009; 49: 537-41.

44. Suh DS, Kim JK, Kim KR, Kim DY, Kim JH, Kim YM, et al. Reliability of magnetic resonance imaging in assessing myometrial invasion absence in endometrial carcinoma. Acta Obstet Gynecol Scand 2009; 88: 990-3.

45. Hacker NF. Uterine cancer. In: Berek JS, Hacker NF, editors. Berek \& Hacker's gynecologic oncology. 5th ed. Philadelphia: Lippincott Williams \& Wilkins; 2010. p.400-17.

46. Kilgore LC, Partridge EE, Alvarez RD, Austin JM, Shingleton $\mathrm{HM}$, Noojin F 3rd, et al. Adenocarcinoma of the endometrium: survival comparisons of patients with and without pelvic node sampling. Gynecol Oncol 1995; 56: 29-33.

47. Chan JK, Wu H, Cheung MK, Shin JY, Osann K, Kapp DS. The outcomes of 27,063 women with unstaged endometrioid uterine cancer. Gynecol Oncol 2007; 106: 282-8.

48. Lee TS, Kim JW, Kim TJ, Cho CH, Ryu SY, Ryu HS, et al. Ovarian preservation during the surgical treatment of early stage endometrial cancer: a nation-wide study conducted by the Korean Gynecologic Oncology Group. Gynecol Oncol 2009; 115: 26-31.

49. Tangjitgamol S, Anderson BO, See HT, Lertbutsayanukul C, Sirisabya N, Manchana T, et al. Management of endometrial cancer in Asia: consensus statement from the Asian Oncology Summit 2009. Lancet Oncol 2009; 10: 1119-27.

50. Lee JM, Lee JK, Kim JW, Cho CH, Kim SM, Park SY, et al. Current status in the management of uterine cancer in Korea: a multi-center retrospective Korean study. The 25th Annual Meeting of Korean Society of Gynecologic Oncology and Colposcopy 2010, Abstract 10S-006.

51. Seo MW, Lee HY, Kim DY, Suh DS, Kim JH, Kim YM, et al. The effect of lymphadenectomy on the survival rate of clinical stage I endometrial cancer. Korean J Gynecol Oncol 2006; 17: 227-33.

52. Chang SJ, Kim WY, Yoon JH, Yoo SC, Chang KH, Ryu HS. Para-aortic lymphadenectomy improves survival in patients with intermediate to high-risk endometrial carcinoma. Acta Obstet Gynecol Scand 2008; 87: 1361-9.

53. Fujimoto T, Nanjyo H, Nakamura A, Yokoyama Y, Takano T, Shoji $\mathrm{T}$, et al. Para-aortic lymphadenectomy may improve disease-related survival in patients with multipositive pelvic lymph node stage IIIc endometrial cancer. Gynecol Oncol 2007; 107: 253-9.

54. Childers JM, Brzechffa PR, Hatch KD, Surwit EA. Laparoscopically assisted surgical staging (LASS) of endometrial cancer. Gynecol Oncol 1993; 51: 33-8.

55. Jung YW, Lee DW, Kim SW, Nam EJ, Kim JH, Kim JW, et al. Robot-assisted staging using three robotic arms for endometrial cancer: comparison to laparoscopy and laparotomy at a single institution. J Surg Oncol 2010; 101: 116-21.

56. Hahn HS, Kim HJ, Yoon SG, Kim WC, Choi HJ, Kim HS, et al. 
Laparoscopy-assisted vaginal versus abdominal hysterectomy in endometrial cancer. Int J Gynecol Cancer 2010; 20: 102-9.

57. Lee JH, Jung US, Kyung MS, Choi JS. Laparoscopic-assisted staging surgery for Korean women with endometrial cancer. JSLS 2008; 12: 150-5.

58. Cho YH, Kim DY, Kim JH, Kim YM, Kim YT, Nam JH. Laparoscopic management of early uterine cancer: 10-year experience in Asan Medical Center. Gynecol Oncol 2007; 106: 585-90.

59. Lee TS, Kim JW, Kim SH, Seong SJ, Song ES, Kim JH, et al. Surgical practice patterns in endometrial cancer: results of the Korean Gynecologic Oncology Group survey. J Gynecol Oncol 2009; 20: 107-12.

60. Lim S, Kim HS, Lee KB, Yoo CW, Park SY, Seo SS. Does the use of a uterine manipulator with an intrauterine balloon in total laparoscopic hysterectomy facilitate tumor cell spillage into the peritoneal cavity in patients with endometrial cancer? Int J Gynecol Cancer 2008; 18: 1145-9.

61. Boronow RC, Morrow CP, Creasman WT, Disaia PJ, Silverberg SG, Miller A, et al. Surgical staging in endometrial cancer: clinical-pathologic findings of a prospective study. Obstet Gynecol 1984; 63: 825-32.

62. Lee TS, Jung JY, Kim JW, Park NH, Song YS, Kang SB, et al. Feasibility of ovarian preservation in patients with early stage endometrial carcinoma. Gynecol Oncol 2007; 104: 52-7.

63. Han CH, Lim SY, Kook IY, Lee KH, Namkoong SE, Park JS, et al. Prognostic outcome of patients with clinical stage I-II endometrial cancer according to bilateral salpino-oophorectomy. Korean J Obstet Gynecol 2007; 50: 288-94.

64. Yoo SC, Yoon JH, Kim WY, Chang SJ, Joo HJ, Chang KH, et al. Premenopausal early-stage endometrial carcinoma patients with low CA-125 levels and low tumor grade may undergo ovary-saving surgery. J Gynecol Oncol 2009; 20: 181-6.

65. Creutzberg CL, van Putten WL, Koper PC, Lybeert ML, Jobsen JJ, Warlam-Rodenhuis CC, et al. Survival after relapse in patients with endometrial cancer: results from a randomized trial. Gynecol Oncol 2003; 89: 201-9.

66. Keys HM, Roberts JA, Brunetto VL, Zaino RJ, Spirtos NM, Bloss JD, et al. A phase III trial of surgery with or without adjunctive external pelvic radiation therapy in intermediate risk endometrial adenocarcinoma: a Gynecologic Oncology Group study. Gynecol Oncol 2004; 92: 744-51.

67. Johnson N, Cornes P. Survival and recurrent disease after postoperative radiotherapy for early endometrial cancer: systematic review and meta-analysis. BJOG 2007; 114: 1313-20.

68. Kim S, Wu HG, Lee HP, Kang SB, Song YS, Park NH, et al. Patterns of failure after postoperative radiation therapy for endometrial carcinoma. Cancer Res Treat 2006; 38: 133-8.

69. Randall ME, Filiaci VL, Muss H, Spirtos NM, Mannel RS, Fowler J, et al. Randomized phase III trial of whole-abdominal irradiation versus doxorubicin and cisplatin chemotherapy in advanced endometrial carcinoma: a Gynecologic Oncology Group Study. J Clin Oncol 2006; 24: 36-44.

70. Hogberg T, Rosenberg P, Kristensen G, de Oliveira CF, de Pont Christensen R, Sorbe B, et al. A randomized phase-III study on adjuvant treatment with radiation (RT) \pm chemotherapy (CT) in early-stage high-risk endometrial cancer (NSGO-EC-9501/ EORTC 55991). J Clin Oncol 2007; 25(18S): 5503.

71. Kim JH, Lee SJ, Bae JH, Lee SH, Bae SN, Namkoong SE, et al. Adjuvant therapy in high-risk early endometrial carcinoma: a retrospective analysis of 46 cases. J Gynecol Oncol 2008; 19: $236-40$.

72. Choi MC, Park JH, Kim SH, Jun KH, Jung SG, Na YJ, et al. Comparison of postoperative radiotherapy versus postoperative paclitaxel and platinum chemotherapy in uterine endometrial carcinoma. Korean J Obstet Gynecol 2008; 51: 1280-7.

73. Gotlieb WH, Beiner ME, Shalmon B, Korach Y, Segal Y, Zmira $\mathrm{N}$, et al. Outcome of fertility-sparing treatment with progestins in young patients with endometrial cancer. Obstet Gynecol 2003; 102: 718-25.

74. Ushijima K, Yahata H, Yoshikawa H, Konishi I, Yasugi T, Saito $\mathrm{T}$, et al. Multicenter phase II study of fertility-sparing treatment with medroxyprogesterone acetate for endometrial carcinoma and atypical hyperplasia in young women. J Clin Oncol 2007; 25: 2798-803.

75. Park JC, Cho $\mathrm{CH}$, Rhee JH. A successful live birth through in vitro fertilization program after conservative treatment of FIGO grade I endometrial cancer. J Korean Med Sci 2006; 21: 567-71.

76. Cho YH, Suh DS, Ji YI, Kim DY, Kim JH, Kim YM, et al. Treatment efficacy of high dose progestin in young women with early stage of endometrial carcinoma. Korean J Obstet Gynecol 2007; 50: 486-93.

77. Han AR, Kwon YS, Kim DY, Kim JH, Kim YM, Kim YT, et al. Pregnancy outcomes using assisted reproductive technology after fertility-preserving therapy in patients with endometrial adenocarcinoma or atypical complex hyperplasia. Int J Gynecol Cancer 2009; 19: 147-51.

78. Hahn HS, Yoon SG, Hong JS, Hong SR, Park SJ, Lim JY, et al. Conservative treatment with progestin and pregnancy outcomes in endometrial cancer. Int J Gynecol Cancer 2009; 19: 1068-73.

79. Kizer NT, Zighelboim I, Case AS, Dewdney SB, Thaker PH, Massad LS. The role of PET/CT in the management of patients with cervical cancer: practice patterns of the members of the Society of Gynecologic Oncologists. Gynecol Oncol 2009; 114: 310-4.

80. Chung HH, Kang WJ, Kim JW, Park NH, Song YS, Chung JK, et al. The clinical impact of [(18)F]FDG PET/CT for the management of recurrent endometrial cancer: correlation with clinical and histological findings. Eur J Nucl Med Mol Imaging 2008; 35: 1081-8.

81. Park JY, Kim EN, Kim DY, Kim JH, Kim YM, Kim YT, et al. Clinical impact of positron emission tomography or positron emission tomography/computed tomography in the posttherapy surveillance of endometrial carcinoma: evaluation of 88 patients. Int J Gynecol Cancer 2008; 18: 1332-8.

82. Engelsen IB, Akslen LA, Salvesen HB. Biologic markers in endometrial cancer treatment. APMIS 2009; 117: 693-707.

83. Jeon YT, Kang S, Kang DH, Yoo KY, Park IA, Bang YJ, et al. Cyclooxygenase-2 and p53 expressions in endometrial cancer. Cancer Epidemiol Biomarkers Prev 2004; 13: 1538-42.

84. No JH, Jeon YT, Park IA, Kang D, Kim JW, Park NH, et al. Expression of mTOR protein and its clinical significance in endometrial cancer. Med Sci Monit 2009; 15: BR301-5.

85. Cho H, Kang ES, Kim YT, Kim JH. Diagnostic and prognostic impact of osteopontin expression in endometrial cancer. Cancer Invest 2009; 27: 313-23.

86. Lee EJ, Kim TJ, Kim DS, Choi CH, Lee JW, Lee JH, et al. p53 alteration independently predicts poor outcomes in patients with endometrial cancer: a clinicopathologic study of 131 cases and literature review. Gynecol Oncol 2010; 116: 533-8.

87. An HJ, Kim KI, Kim JY, Shim JY, Kang H, Kim TH, et al. Microsatellite instability in endometrioid type endometrial adenocarcinoma is associated with poor prognostic indicators. Am J Surg Pathol 2007; 31: 846-53.

88. Kim JW, Song JY, Lee JM, Lee JK, Lee NW, Yeom BW, et al. Expression of pituitary tumor-transforming gene in endometrial cancer as a prognostic marker. Int J Gynecol Cancer 2008; 18: 1352-9.

89. Powell JL, Hill KA, Shiro BC, Diehl SJ, Gajewski WH. 
Preoperative serum CA-125 levels in treating endometrial cancer. J Reprod Med 2005; 50: 585-90.

90. Rittling SR, Chambers AF. Role of osteopontin in tumour progression. Br J Cancer 2004; 90: 1877-81.

91. Ji YI, Kim MK, Kim DY, Suh DS, Kim JH, Kim YM, et al. Clinical analysis of recurrent and advanced saged endometrial cancer. Korean J Gynecol Oncol Colposc 2004; 15: 294-300.

92. Choi ES, Jung MH, Ma GY, Lee SJ, Kim DY, Kim JH, et al. The efficacy of paclitaxel based combination chemotherapy in recurrent endometrial cancer. Korean J Gynecol Oncol 2005; 16: 163-8.

93. Creasman WT, Henderson D, Hinshaw W, Clarke-Pearson DL. Estrogen replacement therapy in the patient treated for endometrial cancer. Obstet Gynecol 1986; 67: 326-30.

94. Chapman JA, DiSaia PJ, Osann K, Roth PD, Gillotte DL, Berman ML. Estrogen replacement in surgical stage I and II endometrial cancer survivors. Am J Obstet Gynecol 1996; 175:
1195-200.

95. Suriano KA, McHale M, McLaren CE, Li KT, Re A, DiSaia PJ. Estrogen replacement therapy in endometrial cancer patients: a matched control study. Obstet Gynecol 2001; 97: 555-60.

96. Ayhan A, Taskiran C, Simsek S, Sever A. Does immediate hormone replacement therapy affect the oncologic outcome in endometrial cancer survivors? Int J Gynecol Cancer 2006; 16 : 805-8.

97. Barakat RR, Bundy BN, Spirtos NM, Bell J, Mannel RS. Randomized double-blind trial of estrogen replacement therapy versus placebo in stage I or II endometrial cancer: a Gynecologic Oncology Group Study. J Clin Oncol 2006; 24: 587-92.

98. Lee KB, Lee JM, Lee JK, Cho CH. Endometrial cancer patients and tibolone: a matched case-control study. Maturitas 2006; 55 : 264-9.

\section{Standards for Different Types of Articles}

Guidelines for six different types of articles have been adopted by the Journal of Gynecologic Oncology:

1. CONSORT (Consolidated Standards of Reporting Trials) standards for reporting randomized trials

2. PRISMA (Preferred Reporting Items for Systematic Reviews and Meta-analyses) guidelines for reporting systematic reviews and meta-analyses

3. MOOSE (Meta-analysis of Observational Studies in Epidemiology) guidelines for meta-analyses and systematic reviews of observational studies

4. STROBE (Strengthening the Reporting of Observational Studies in Epidemiology) guidelines for the reporting of observational studies

5. STARD (Standards for Reporting of Diagnostic Accuracy) standards for reporting studies of diagnostic accuracy

6. REMARK (Reporting of tumor Markers Studies) guidelines for reporting tumor marker prognostic studies

Investigators who are planning, conducting, or reporting randomized trials, meta-analyses of randomized trials, meta-analyses of observational studies, observational studies, studies of diagnostic accuracy, or tumor marker prognostic studies should be familiar with these sets of standards and follow these guidelines in articles submitted for publication.

NOW AVAILABLE ONLINE - http://www.ejgo.org 